declared, H. Hammer: None declared, I. Olsen: None declared, T. Uhlig: None declared, D. van der Heijde: None declared, T. Kvien: None declared, E. Haavardsholm Grant/research support from: Pfizer, UCB, Roche, MSD, and AbbVie DOI: 10.1136/annrheumdis-2018-eular.5318

\section{OP0151 ROUTINELY RECORDED MUSCULOSKELETAL ULTRASOUND FINDINGS IMPACT CLINICIANS' DIAGNOSTIC BEHAVIOUR MAXIMALLY IN AUTOANTIBODY-SERONEGATIVE PATIENTS ATTENDING AN EARLY ARTHRITIS CLINIC}

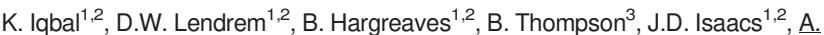
G. Pratt ${ }^{1,2}$. ${ }^{1}$ National Institute for Health Research Newcastle Biomedical Research Centre, Newcastle upon Tyne Hospitals NHS Foundation Trust and Newcastle University, ${ }^{2}$ Institute of Cellular Medicine, Newcastle University, ${ }^{3}$ Muskuloskeletal Directorate, Newcastle upon Tyne Hospitals NHS Foundation Trust, Newcastle Upon Tyne, UK

Background: Musculoskeletal ultrasound (MSUS) is a popular assessment tool, but its contribution to diagnostic practice over and above standard clinical and laboratory parameters has proved difficult to quantify.

Objectives: A published 7-joint ultrasound algorithm ${ }^{1}$ has been adapted for pragmatic application during 15 min screening appointments forming part of initial patient assessments in the Newcastle Early Arthritis Clinic (NEAC). Its additive contribution to diagnostic classification in this routine setting was appraised.

Methods: Detailed baseline clinical and laboratory parameters were recorded. Semi-quantitative MSUS scoring (0-3, grey scale and power Doppler) of the most symptomatic wrist (midline and ulnar dorsal longitudinal views), 2nd/3rd MCPs and PIPs and 2nd/5th MTPs (all longitudinal views) was recorded by sonographers, along with the 'sonographer's scan impression' ('definitely inflammatory, 'possibly inflammatory' or 'non-inflammatory'). All MSUS findings were available to rheumatologist diagnosticians during subsequent consultations, and persistent inflammatory arthritis (PIA) was classified only where patients were started on $\geq 1$ disease modifying anti-rheumatic drug (DMARD). Stepwise multiple logistic regression was employed to identify clinical variables that independently predicted IA diagnosis; the additive contribution of MSUS parameters to resultant models was assessed by comparing areas under receiver operator characteristic curves (AU ROCs).

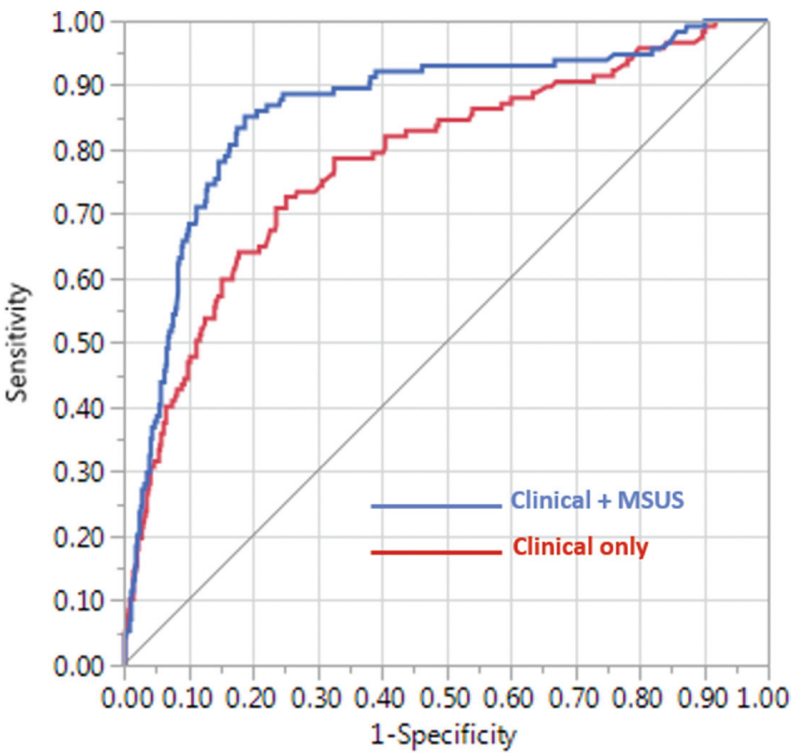

Abstract OP0151 - Figure 1 ROC curves depicting additive discriminatory utility of MSUS 'scan impression' with clinical parameters alone (red), with respect to PIA diagnosis amongst seronegative early arthritis patients. $\triangle \mathrm{AU} A O C=0.08 ; \mathrm{p}<0.001$

Results: 847 patients were enrolled (17\% seropositive for anti-citrullinated peptide autoantibody, ACPA); final outcomes of PIA were recorded in $29 \%$ and $18 \%$ of the overall and ACPA-seronegative cohorts, respectively. SJC, CRP, age and ACPA status were non-redundant clinical/laboratory predictors of a PIA diagnosis by consulting rheumatologists in the overall cohort (AU ROC $0.85 ; 95 \% \mathrm{Cl}: 0.81$ to 0.88 ), their discriminatory utility being diminished in the seronegative subcohort (AU ROC $0.78 ; 95 \% \mathrm{Cl}: 0.72$ to 0.82 ). Although the additive contribution of summed parameters from the 7-joint MSUS algorithm to the model was statistically significant $(\mathrm{p}<0.001)$ it was numerically small (delta-AU ROC 0.03 and 0.05 in the overall and seronegative cohorts, respectively). The 'sonographer's scan impression' was a potentially more useful diagnostic tool, its additive contribution to diagnostic outcome over clinical parameters alone being most evident in ACPA-negative patients where it increased the AU ROC by $10 \%$ (delta-AU ROC $0.08 ; p<0.001$; figure 1 )

Conclusions: In this large, un-blinded observational study, the clinical utility of a 15 min MSUS screen for diagnosing PIA requiring DMARDs was particularly evident amongst ACPA negative patients attending an EA clinic.

\section{REFERENCE:}

[1] Backhaus, et al. Arthritis Rheumatol 61:1194-201.

Acknowledgements: National Institute for Health Research Newcastle Biomedical Research Centre

Disclosure of Interest: None declared

DOI: 10.1136/annrheumdis-2018-eular.3893

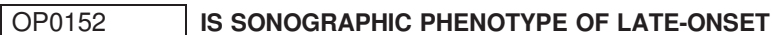 RHEUMATOID ARTHRITIS DIFFERENT FROM YOUNG- ONSET RHEUMATOID ARTHRITIS? RESULTS FROM THE BIRMINGHAM EARLY ARTHRITIS COHORT}

$\underline{\text { R Singh }}{ }^{1,2}$, I. Sahbudin ${ }^{1,2}$, M. Maybury ${ }^{1}$, K. Raza ${ }^{1,3}$, A. Filer ${ }^{1,2} .{ }^{1}$ Rheumatology Research Group, Institute of Inflammation and Ageing, University Hospitals of Birmingham; ${ }^{2}$ Department of Rheumatology, University Hospitals Birmingham NHS Foundation Trust, Queen Elizabeth Hospital Birmingham; ${ }^{3}$ Department of Rheumatology, Sandwell and West Birmingham Hospitals NHS Trust, Birmingham, UK

Background: The incidence of rheumatoid arthritis (RA) is generally seen as a bimodal age distribution, which consists of young-onset RA (YORA) and lateonset RA (LORA). Although a retrospective study has reported some differences in sonographic changes between LORA and YORA, little is known whether there are any differences in the clinical and sonographic phenotypes between these two groups during the early disease phases.

Objectives: To compare the clinical and sonographic characteristics between YORA and LORA during the early phases of disease.

Methods: DMARD-naïve patients with clinically apparent synovitis of at least one joint and symptom duration of three months or less were included in the analysis. Patients underwent clinical, ultrasonography and radiological assessments at baseline and final outcomes were determined at 18 months; patients were classified as having RA (according to either the 1987 ACR and/or 2010 ACR/EULAR criteria), a non-RA persistent arthritis or a resolving arthritis. Sonographic assessment included MCP, PIP, wrist, MTP, knee, ankle, elbow joints and wrist, hand flexor, bicep tendon, anteromedial-lateral tendon compartments. The presence and absence of joint synovitis and tenosynovitis were recorded according to the EULAR/OMERACT consensus definition.

\begin{tabular}{|c|c|c|c|c|c|c|}
\hline & & $\begin{array}{c}\text { Young- } \\
\text { onset RA } \\
(n=37)\end{array}$ & $\begin{array}{l}\text { Late- } \\
\text { onset RA } \\
(n=36)\end{array}$ & $\begin{array}{c}\text { Non-RA } \\
\text { persistent } \\
\text { arthritis }(n=27)\end{array}$ & $\begin{array}{l}\text { Resolving } \\
\text { arthritis } \\
(n=50)\end{array}$ & $\begin{array}{c}\text { P (YORA } \\
\text { vs } \\
\text { LORA) }\end{array}$ \\
\hline \multicolumn{2}{|c|}{ Age (years) } & $50(45-56)$ & $\begin{array}{c}67(63- \\
73)\end{array}$ & $39(31-60)$ & $46(35-59)$ & $<0.001$ \\
\hline \multicolumn{2}{|c|}{ EMS (mins) } & $\begin{array}{c}75(30- \\
120)\end{array}$ & $\begin{array}{c}120(60- \\
240)\end{array}$ & $60(10-180)$ & $30(0-68)$ & 0.808 \\
\hline \multicolumn{2}{|c|}{ DAS-28 CRP } & $\begin{array}{c}5.02(3.60- \\
5.73)\end{array}$ & $\begin{array}{c}5.11 \\
(4.49- \\
6.10)\end{array}$ & $3.77(3.02-4.95)$ & $\begin{array}{c}3.35(2.98- \\
4.43)\end{array}$ & 1.00 \\
\hline \multirow[t]{3}{*}{ RF\% } & $\begin{array}{l}\text { High } \\
\text { Positive }\end{array}$ & $15(40.5)$ & $10(27.8)$ & $1(3.7)$ & $2(4)$ & 0.568 \\
\hline & $\begin{array}{l}\text { Low } \\
\text { Positive }\end{array}$ & $5(13.5)$ & 7 (19.4) & $4(14.8)$ & $1(2)$ & \\
\hline & Negative & 17 (45.9) & $19(52.8)$ & $22(81.5)$ & $47(94)$ & \\
\hline \multirow[t]{3}{*}{$\begin{array}{l}\text { ACPA } \\
\%\end{array}$} & $\begin{array}{c}\text { High } \\
\text { positive }\end{array}$ & $17(45.9)$ & 14 (38.9) & $2(7.4)$ & $2(4)$ & 0.722 \\
\hline & $\begin{array}{l}\text { Low } \\
\text { positive }\end{array}$ & $1(2.7)$ & $2(5.6)$ & $0(0.0)$ & $0(0.0)$ & \\
\hline & Negative & $19(51.4)$ & $20(55.6)$ & $25(92.6)$ & $48(96.0)$ & \\
\hline \multicolumn{2}{|c|}{$\begin{array}{l}\text { Symptom } \\
\text { duration (weeks) }\end{array}$} & $8(4-10)$ & $8(6-10)$ & $6(4-8)$ & $5(4-8)$ & 1.00 \\
\hline \multicolumn{2}{|c|}{$\begin{array}{l}\text { Bilateral MTP } \\
\text { squeeze, n (\%) }\end{array}$} & $22(59.5)$ & $10(27.8)$ & $4(14.8)$ & $10(20.0)$ & 0.09 \\
\hline
\end{tabular}

Results: 150 patients were included in the analysis. At 18 months, 37 patients developed YORA, 36 developed LORA, 27 developed non-RA inflammatory arthritis and 50 patients had resolving arthritis. The clinical characteristics 